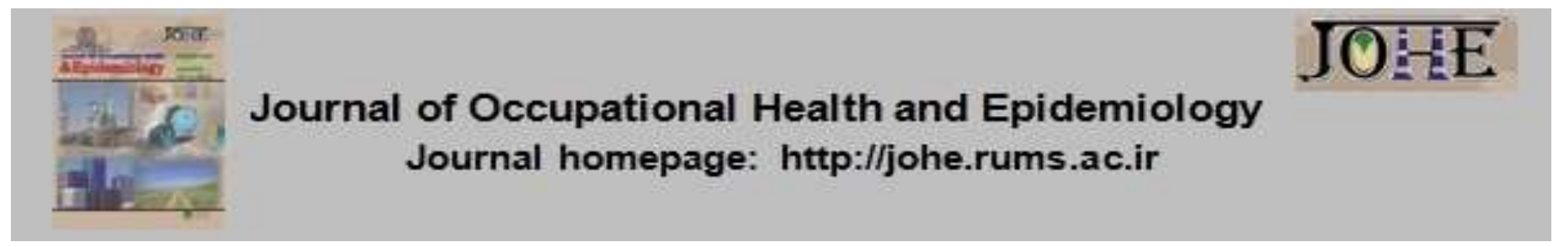

\title{
Association between Job Satisfaction and Occupational Accidents among Operating Staff at a Cement Factory, 2018
}

\author{
Fereshteh Jahani ${ }^{1}$, Zeinab Mosavian Asl $^{2}$, Bahram Kouhnavard ${ }^{3}$, Shoaib Shamsaddini ${ }^{4}$
}

1. MSc in Occupational Health Engineering, Dept. of Occupational Health Engineering, School of Public Health, Ahvaz Jundishapur University of Medical Sciences, Ahvaz, Iran; Instructor, Dept. of Safety Engineering, Lamerd Higher Education Center, Lamerd, Iran.

2. MSc in Occupational Health Engineering, Dept. of Occupational Health Engineering, School of Public Health, Ahvaz Jundishapur University of Medical Sciences, Ahvaz, Iran.

3. PhD Student in Ergonomics, Dept. of Occupational Health Engineering, School of Public Health, Tehran University of Medical Sciences, Tehran, Iran.

4. MSc in Epidemiology, Dept. of Epidemiology, School of Public Health, Jundishapour University of Medical Sciences, Ahvaz, Iran.

\section{Article Info}

* Corresponding author:

Bahram Kouhnavard,

E-mail:

b-kouhnavard@razi.tums.ac.ir

\section{Article history}

Received: Sep 2020

Accepted: Jan 2021

10.29252/johe.9.3.189

Print ISSN: 2251-8096 Online ISSN: 2252-0902

Peer review under responsibility of Journal of Occupational Health and Epidemiology
Citation: Jahani F, Mosavian AsI Z, Kouhnavard B, Bahmanziari M. Association between Job Satisfaction and Occupational Accidents among Operating Staff at a Cement Factory, 2018. JOHE 2020; 9(3):189-93.

\section{Abstract}

Background: Job Satisfaction can lead to better performance and a reduction in occupational accidents, thereby increasing organizational productivity. This study aims to investigate the relationship between job satisfaction and occupational accidents in the operating staff of a cement industry.

Materials and Methods: This descriptive study was conducted at Lamerd Cement Factory in the Fars Province. All employees at that factory were considered the target population of the study $(n=53)$. The census method was used in this study to assess the incidence rate and to complete the job satisfaction questionnaire. Besides, data analysis was performed using the independent samples t-test and the one-way ANOVA in SPSS 24.

Results: The average job satisfaction is correlated with the number of accidents ( $p=$ 0.003), which shows people with more than once accident have less job satisfaction. Besides, the number of trainings has a direct correlation with the average job satisfaction $(P=0.016)$, and married people are more satisfied than single ones.

Conclusion: Occupational hazard evaluations have a direct effect on the level of job satisfaction. Due to the direct relationship between training and the increase in job satisfaction, providing relevant trainings is emphasized.

Keywords: Job Satisfaction, Accident, Industry.

\section{Introduction}

In today's world, various industries play a leading role in economic growth and production of societies. In contrast to large industries, such as oil, gas, and automotive industries, safety and health of employees may be neglected in small industries for different reasons, such as financial problems and market fluctuations [1].

The cement industry in Iran plays a leading role among other industries and is considered a strategic industry. Products of the cement industry play a key role in many infrastructure projects and increase the power of competition in international trade. Accordingly, about 70 million tons of cement is produced annually in Iran, with Iran being one of the largest cement exporters in the world [2].

Job satisfaction affects many organizational variables. Research shows that job satisfaction is an effective factor in enhancing productivity, employee empathy for the organization, and their 
interest in the workplace; in addition, it increases quality and quantity of the work, builds good human relationships at work, and raises employee interest in the work [3]. Job satisfaction is the sense of satisfaction in a person with their organizational job, which is caused by the congruity between the work and talents, the degree of job success, provision of logical factors, prosperity of talented individuals, job progress, successful experiences, and organizational climate [4]. Job satisfaction is effective in reducing accidents and damage caused by the work, protecting employee health, as well as reducing costs of accidents and damage. In this context, employee motivation increases, thereby improving employee performance and the quality of organizational performance. Research on job satisfaction shows that it could be achieved in different environments for different groups, which has different aspects and dimensions. Some studies report that Increasing the salary and payment, job equity, modifying working time and shift plans, providing opportunities for the employees to further their carriers, and continuing education are important issues in increasing job satisfaction [5-7].

In the research conducted in Finland, it was found out that employees with less job satisfaction were more negatively affected by accidents, or accidents were more damaging to them [8]. Annual job incidents (2005) have been responsible for more than 300,000 deaths and have hurt more than 300 million people worldwide [9-11]. This large number of accidents causes severe human and financial damage to communities [12]. Most of occupational accidents are preventable. Apart from disability, loss of income, and changes in workers' quality of life and their family life, occupational accidents also exert considerable adverse effects on the production and economy of the country [13]. Thus, the increase in financial costs of workrelated accidents reflects the effect of this issue on employee job satisfaction.

Job satisfaction, against the presence of a variety of harmful factors in the workplace, can lead to better performance and reduced job accidents, thereby increasing organizational productivity. In this context, sufficient satisfaction with working conditions increases employee motivation and improves organizational performance. This study aims to investigate the relationship between employee job satisfaction with harmful factors in the workplace and the occurrence of occupational accidents among employees of a cement factory.

\section{Materials and Methods}

In this descriptive study, all 53 employees of the operations and mechanics department of a cement factory entered the study by the census method. The participants were selected from the three departments of cement, cooking, and raw materials, because of the stable working shifts in each department. Next, they were studied in terms of the rate of accidents by filling out the job satisfaction questionnaire. The common features of the mentioned three departments include the contact of employees with machines and dangerous equipment as well as their exposure to harmful elements, such as dust, noise, and heat tensions.

In this study, the research objectives and process were explained to the subjects, and they were informed on the voluntary nature of the participation in the study. In addition, written informed consent was obtained from all individuals, they were ensured about confidentiality of their information, and ethical standards were met. Besides, the present research received no specific funding from any funding agency in the public, commercial, or not-for-profit sectors.

Data collection was carried out using the two demographic and job satisfaction questionnaires. These two questionnaires measured harmful factors, noise, heat tensions, and dust. In addition, demographic data included age, work experience, education, marital status, number of safety trainings, and number of occupational accidents.

To measure job satisfaction in this study, the Minnesota job satisfaction questionnaire was used. This questionnaire has 20 questions, with the purpose of which being to review job satisfaction in six dimensions of the payment system, job type, development opportunities, organizational environment, leadership style, and physical conditions in Iran [14]. These questions have been used in different studies, including those of Mohammadi, Khandan, and Doostkam [15-16]. In the present study, the questions were rated on a five-point Likert scale, which included totally agree $=5$, agree $=4$, not being sure $=3$, disagree $=2$, and totally disagree $=1$. In addition, the MSQ utilized a five-point Likert scale, including 1 =very dissatisfied, 2=dissatisfied, 3=neutral, $4=$ satisfied, and $5=$ very satisfied. Reliability of the questionnaire in this study was 0.86., and its validity was reported to be acceptable in Iran. The highest score that could be obtained in the questionnaire is 100 , and the lowest score is 20 ; 
besides, score 60 corresponds to the middle point representing neutral satisfaction. When a score approaches 20, the level of satisfaction decreases, and when it approaches 100, the level of satisfaction increases. The Minnesota job satisfaction questionnaire consists of 20 items and 3 subscales, with features determining low, medium, and high levels of satisfaction [17].

The numbers reported in the section of pollutants were taken from results of the annual pollution test at the factory. Data analysis was performed using an independent samples t-test, the Pearson's correlation test, and the one-way ANOVA in SPSS 24.

\section{Results}

The mean age of the participants was $33.49 \pm 5.10$ years, and their average work experience was 7.74 \pm 3.72 years. Besides, the average job satisfaction score was $67.62 \pm 12.30$, and $\% 92.45$ of the participants were married, with all of them having been male. Most of the participants had a high school diploma (\%52.83), and \%60.37 of them had no experience of any accidents. Besides, \%8 of the employees had not received any trainings. Table 1 shows other demographic data of the participants in the study.

Results of the independent samples t-test showed that there was a significant difference between the mean score of job satisfaction in the married employees and the single ones; accordingly, the married employees had a higher level of job satisfaction than the single ones $(P=0.040)$.

Table 1. Distribution of the subjects' demographic characteristics

\begin{tabular}{|c|c|c|c|}
\hline \multicolumn{2}{|c|}{ Variables } & Number & Percent \\
\hline \multirow{4}{*}{ Educational level } & High school diploma & 28 & 52.83 \\
\hline & Associate's degree & 11 & 20.75 \\
\hline & BSc & 13 & 34.52 \\
\hline & MSc & 1 & 1.88 \\
\hline \multirow{3}{*}{ Number of accidents } & 0 & 32 & 60.37 \\
\hline & 1 & 14 & 26.41 \\
\hline & 2 & 7 & 13.20 \\
\hline \multirow{6}{*}{$\begin{array}{c}\text { Number of trained } \\
\text { workers }\end{array}$} & 0 & 1 & 0.8 \\
\hline & 1 & 14 & 10.8 \\
\hline & 2 & 12 & 9.2 \\
\hline & 3 & 14 & 10.8 \\
\hline & 4 & 5 & 3.8 \\
\hline & 5 & 7 & 5.4 \\
\hline \multirow{2}{*}{ Marital status } & Single & 4 & 7.54 \\
\hline & Married & 49 & 92.45 \\
\hline
\end{tabular}

According to Table 2, the average job satisfaction score of employees for the educational level showed that employees with an associate's degree had the highest average job satisfaction score and standard deviation of $68.90 \pm 4.13$. In addition, employees with an MSc and higher education levels had the lowest average job satisfaction score (2.95). Results of the Pearson's correlation test showed no significant relationship between age and job satisfaction ( $p=0.362$ ). In addition, job satisfaction had a significant relationship with education $(p=0.657)$ and work experience $(p=$ 0.331).

Table 2. Comparison of average job satisfaction scores among people with different levels of education

\begin{tabular}{ccccc}
$\begin{array}{c}\text { Job satisfaction and } \\
\text { education }\end{array}$ & $\mathbf{N}$ & Mean & $\begin{array}{c}\text { Standard } \\
\text { deviation }\end{array}$ & P-value \\
\hline High school & 28 & 66.92 & 2.51 & \multirow{2}{*}{$0.657^{\star}$} \\
\hline Associate's degree & 11 & 68.90 & 4.13 & \\
\hline BSc & 13 & 68.69 & 2.63 & \\
\hline MSc & 1 & 59.00 & 0.00 & \\
\hline Total & 53 & 67.62 & 12.30 & \\
\hline
\end{tabular}

* The one-way ANOVA test at a significance level of 0.05

As Table 3 shows, the average job satisfaction scores of the cement factory employees have been calculated in terms of the number of accidents. Accordingly, individuals with more accidents (2 
events and more) had lower average job satisfaction scores. Besides, the average job satisfaction variable had a statistically significant relationship with the number of accidents ( $p=$ 0.003), which shows that people with more than once accident had a lower job satisfaction level.

Table 3. Comparison of average job satisfaction scores among people with different number of accidents

\begin{tabular}{cccc}
\hline Number of accidents & Average job satisfaction & Standard deviation & P-value \\
\hline $\mathbf{0}$ & 68.46 & 2.00 & \\
\hline $\mathbf{1}$ & 69.92 & 3.75 & $0.003^{*}$ \\
\hline $\mathbf{2}$ or more & 59.14 & 4.13 & \\
\hline Total & 67.62 & 12.30 & \\
\hline
\end{tabular}

* The one-way ANOVA test at a significance level of 0.05

According to Table 4, employees with a higher number of trainings received had a higher job satisfaction score. Based on the results of the oneway ANOVA test, there is a significant relationship between the average job satisfaction score and the number of different safety trainings received $(p=$
0.016). However, according to the Pearson's correlation test, the number of trainings has a significant relationship with the number of accidents ( $p=0.399$ ); accordingly, this indicates that employees having received a higher number of trainings are less likely to have accidents.

Table 4. Comparison of average job satisfaction scores in employees with different numbers of safety trainings received

\begin{tabular}{cccc}
\hline Number of safety trainings & Average job satisfaction score & Standard deviation & P-value \\
\hline $\mathbf{0}$ & 71.00 & 0.00 \\
\hline $\mathbf{1}$ & 63.21 & 3.70 \\
\hline $\mathbf{2}$ & 68.33 & 2.84 & \multirow{2}{*}{$0.016^{\star}$} \\
\hline $\mathbf{3}$ & 67.00 & 3.29 \\
& & 6.90 \\
\hline $\mathbf{4}$ & 67.80 & 3.78 \\
\hline Total & 75.85 & 12.30 \\
\hline
\end{tabular}

* The one-way ANOVA test at a significance level of 0.05

\section{Discussion}

Job satisfaction, according to many experts, is one of the most challenging organizational concepts and the basis for formulating management policies to enhance organizational productivity and efficiency 18. The average job satisfaction score of the participants of this study was $67.62 \pm 12.30$, which is based on the categories and levels of job satisfaction. Zare, in his study, achieved a similar result [19]. In the current study, there was no significant relationship between job satisfaction and age, education, and work experience. The study of Faramarzpoor et al on age and job satisfaction reported no significant relationship between them, being consistent with the current study [20]. The same result was obtained in the study of Monjamed et al [21] and that of Movahhed [22]. However, in the study of Tourangean, a significant relationship was reported between age and job satisfaction [23]. Nevertheless, in the study of Asghari et al, a significant relationship was reported between age and job satisfaction because with an increase in age, satisfaction levels increased [24]. In addition, Arab reported that there was no significant relationship between job satisfaction with job experience and marital status, being inconsistent with the results of the present study [25]. Results of data analysis, in the present study, revealed that people with higher education levels had higher job satisfaction levels; in contrast, people with fewer accidents had lower job satisfaction levels.

\section{Conclusion}

The results indicate that the periodic evaluation of occupational hazards has a direct positive effect on the job satisfaction level. Some of the limitations of this research could be lack of accuracy in answering the questionnaire and the small size of the sample. To achieve more precise results, limitations above are suggested to be removed in future studies.

\section{Acknowledgement}

The authors would like to express their sincere gratitude to all staff who participated in the current research.

Conflict of interest: None declared. 


\section{References}

1. Khanijazani R, Tabatabaeii S, Seyed Mehdi S, Kavousi A. Ergonomic study of the relationship between job stress and harmful factors in the cement industry. Iran Occupational Health 2016; 13(2):58-67.

2. Zamanian Z, Azad P, Ghaderi F, Bahrami S, Kouhnavard B. Investigate the Relationship between Rate of Sound and Local Lighting with Occupational Stress among Dentists in the City of Shiraz. Journal of Health 2016; 7(1):87-94.

3. Hooman $\mathrm{H}$. Preparing and standardizing of scale of job satisfaction evaluation. Tehran: Presidential Governmental Management Training Center; 2002.

4. Mirkamali SM. Behavior and relationships in the organization and management. 3rd ed, Tehran: Yastoroon Publication, 2001.

5. Zamanian Z, Norouzi F, Esfandiari Z, Rahgosai M, Hasan F, Kohnavard B. Assessment of the prevalence of musculoskeletal disorders in nurses . Armaghane-e-Danesh 2017; 21(10):976-86.

6. Mirzabeigi Gh, Salemi S, Sanjari M, Shirazi F, Heidari Sh, Maleki S. Job Satisfaction among Iranian Nurses. Hayat 2009; 15(1):49-59.

7. Zamanian Z, Zakian S, Jamali M, Kouhnavard B. The Relationship between Personality Traits, Stress and Job Satisfaction of Employees of Iran Telecom Companies. Journal of Occupational Hygiene Engineering 2015; 1(4):11-18

8. Amiri M, Ardeshir A, Faze Zarandi MH. RiskBased Analysis of Construction Accidents in Iran during 2007-2011-Meta Analyze Study. Iranian Journal of Public Health 2014; 43(4):507-22.

9. Warch SL. Quantifying the Financial Impact of Occupational Injuries and Illnesses, and the Costs and Benefits Associated with an Ergonomic Risk Control Intervention within the Uniprise Business Segment of United Health Group [MSc thesis]. Menomonie, Wisconsin, United States: University of Wisconsin; 2002.

10. Macedo AC, Silva IL. Analysis of occupational accidents in Portugal between 1992 and 2001. Saf Sci 2005; 43(5-6):269-86.

11. Afshari M, Teymori GH, Afshari M, Kohnavard B, Esmail Pour H, Kangavari M. Workers' health literacy in Khodro's piece making factory: a cross-sectional study. Iran Occupational Health 2017; 14(2):147-55.

12. Golmohammadi R, Damyar N, Mohammadfam I, Faradmal J. Evaluation of the relation between noise exposure and occupational stress with unsafe acts and accidents in city bus drivers. Iran Occupational Health 2014; 11(1):70-8.

13. Breslin FC, Smith $P$. Trial by fire: a multivariate examination of the relation between job tenure and work injuries. Occup Environ Med 2006; 63(1):27-32.

14. Hadizadeh Talasaz Z, Nourani Saadoldin S Taghi Shakeri M. The Relationship between Job Satisfaction and Job Performance among Midwives Working in Healthcare Centers of Mashhad, Iran. Journal of Midwifery Reproductive Health 2014; 2(3):157-64.

15. Mohammadi Issaabadi $S$. Investigation of relationship between organizational identity, Job satisfaction and organizational commitment among High School Teachers in Sanandaj [MSc thesis]. Tehran, Iran: University of Tehran; 2007.

16. Doostkam K, Rohollahi AA. The effect of psychological ownership on Job satisfaction of airports supply chain staff (Case study: supply chain part pilot training airport). Iran Occupational Health 2016; 13(3):54-62 .

17. Keskin DOY, Bayram L. A Study on the Job Satisfaction of Physical Education Teachers According to Different Variables. Asian Journal of Education and Training 2020; 6(1): 105-9.

18. Togia A, Konsteliss A, Tsigilis N. Job satisfaction among Greek academic librarians. Libr Inf Sci Res 2004; 26(3):373-83.

19. Zare F, Khademian M, Bahjati Ardakani M, Zare $M$, Parvizi R, Bagharaat $A$. Job stress and its relationship with Job satisfaction in workers of a refinery control room in the south of Iran. Journal of Preventive Medicine 2015; 2(3):47-55

20. Faramarzpour M, Borhani F, Bagheri P. Job Satisfaction of Nurses from Clinical Practice in Jiroft University Hospitals. Iran Journal of Nursing 2015; 28(97):77-86.

21. Monjamed Z, Ghorbani T, Mostofian F, Oveissipour R, Nakhost Pandi S, Mahmoudi M. A nationwide study of level of job satisfaction of nursing personnel in Iran. Journal of Hayat 2005; 10(4):39-48.

22. Movahed MA, Moghaddam YH. Survey of Job Satisfaction and the Factors Affecting it, with Employed Nurses in the Educational and Curative Centers of Uromieh University of Medical Sciences 1380. Nursing and Midwifery Journal 2004; 2(2):27-33.

23. Tourangeau AE, Cummings G, Cranley LA, Ferron EM, Harvey S. Determinants of hospital nurse intention to remain employed: broadening our understanding. J Adv Nurs 2010; 66(1):2232.

24. Asghari E, Khaleghdoust T, Asgari F, Kazemnejad E. Effective factors on nurses' job Satisfaction. Journal of Holistic Nursing and Midwifery 2010; 20(2):1-7.

25. Arab M, Shabaninejad $H$, Rashidian A, Rahimi A, Purketabi K. A survey on working life quality of specialists working in affiliated hospitals of TUMS. Journal of Hospital 2013; 11(4):19-24. 